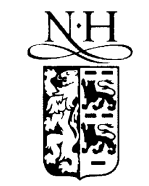

ELSEVIER

\title{
A double cell for X-ray absorption spectrometry of atomic $\mathrm{Zn}$
}

\author{
A. Mihelič ${ }^{\mathrm{a}}$, A. Kodre ${ }^{\mathrm{a}, \mathrm{b}, *}$, I. Arčon $^{\mathrm{a}, \mathrm{c}}$, J. Padežnik Gomilšek ${ }^{\mathrm{d}}$, \\ M. Borowski ${ }^{\text {e }}$ \\ a Jožef Stefan Institute, Jamova 39, 1000 Ljubljana, Slovenia \\ ${ }^{\mathrm{b}}$ Faculty of Mathematics and Physics, University of Ljubljana, Jadranska 19, SI-1000 Ljubljana, Slovenia \\ ${ }^{\mathrm{c}}$ Nova Gorica Polytechnic, Vipavska 13, 5000 Nova Gorica, Slovenia \\ ${ }^{\mathrm{d}}$ Faculty of Mechanical Engineering, University of Maribor, Smetanova 17, 2000 Maribor, Slovenia \\ e European Synchrotron Radiation Facility (ESRF), BP 220, 38043 Grenoble, France
}

Received 4 April 2002; received in revised form 22 May 2002

\begin{abstract}
A high-temperature cell with a double wall design has been constructed for X-ray absorption spectrometry of metal vapors. The inner cell, assembled from a corundum tube and thin plates without welding or reshaping, serves as a container of the vapor sample. It is not vacuum tight: instead, the outer tube provides inert atmosphere. Several spectra of $\mathrm{K}$-edge atomic absorption of $\mathrm{Zn}$ were obtained in the stationary working regime below the $\mathrm{Zn}$ boiling point. The $\mathrm{K}$ edge profile shows an extremely strong resonance and, above the continuum threshold, coexcitations of the outer electrons.
\end{abstract}

(C) 2002 Elsevier Science B.V. All rights reserved.

PACS: 78.70.Dm; 39.90.+d

Keywords: X-ray atomic absorption; Zn vapor; Zn K-edge

Absorption spectrometry of elements in monatomic state is of continuous interest in atomic physics and in structural analysis. A monatomic sample is readily available for elements of noble gas family: indeed, X-ray absorption spectra in the vicinity of K- and L-edges have been studied

\footnotetext{
${ }^{*}$ Corresponding author. Address: Faculty of Mathematics and Physics, University of Ljubljana, Jadranska 19, SI-1000 Ljubljana, Slovenia. Tel.: +386-1-476-6560; fax: +386-1-2517281 .

E-mail address: alojz.kodre@fmf.uni-lj.si (A. Kodre).
}

for most elements of the group [1-5]. The experimental data are used as a test for successive approximations in the theoretical calculation of photoabsorption cross-section. The details of the edge shape and tiny sharp features on the smooth monotonous decrease of the cross-section with energy - the multielectron excitations - reveal some peculiarities of the coupling schemes and configuration interaction in these atoms [6,7].

Apart from noble gases, few elements can be prepared in a monatomic gas state. The volatile elements mostly form bi- or polyatomic molecules, the non-volatiles require complex high-temperature 


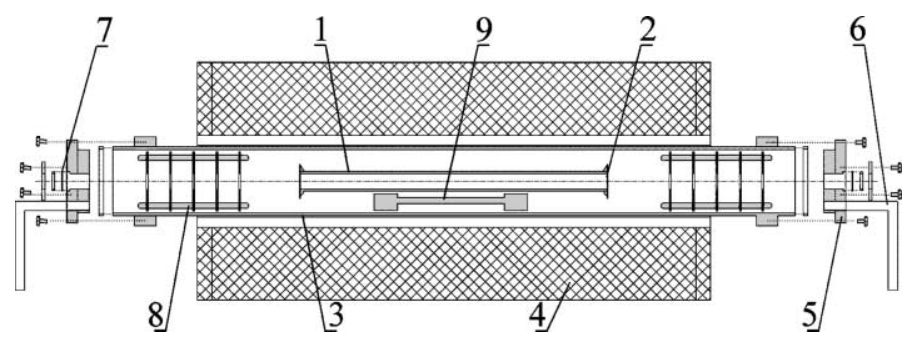

Fig. 1. The double absorption cell for zinc vapor. The labels are explained in the text except (9) - stainless steel cell support.

cells to contain the vapor. The exception is provided by the volatile alkali metals and mercury: the monatomic vapors of these elements have been used in spectrometry, providing the wealth of data comparable to those from noble-gas elements [812]. In addition, it has been shown that the pure atomic absorption represents the best available approximation to the "atomic absorption background" required in the X-ray absorption fine structure (XAFS) methods of structural analysis [13-15].

Among the harder problems - the non-volatile metals - the vapors of $\mathrm{Ca}, \mathrm{Cr}, \mathrm{Mn}, \mathrm{Cu}, \mathrm{Ba}, \mathrm{Hg}$ and some lanthanides have been prepared and contained in a high temperature absorption cell [16-18]. The extremely demanding experiment provided profiles of the K-edge, with important information on the ground state of the atom; the atomic absorption background and the multielectron excitations, however, could not be determined.

Zinc provides a case of a relatively volatile metal, with boiling point at $907^{\circ} \mathrm{C}$. However, the element has a bad reputation among vacuum engineers to adsorb or combine with many of vacuum materials, polluting the system for long afterwards. Preliminary tests in sealed vapor cells of quartz and stainless steel showed that zinc vapor combines with walls too fast for even a single absorption scan. A marginally positive result has been obtained with a brass cell, exploiting the evaporation of zinc from the brass itself. The main problem, as often, are the windows, required to withstand the high temperature, the aggressive vapor and possibly, a substantial pressure difference, while absorbing the incident X-ray beam as little as possible. The brass windows could meet the requirements but would also corrupt the absorption signal of the vapor with the strong structural signal of the zinc in the window alloy.

Another solution is the cell and the windows of corundum: the basic building elements are available, but construction of a sealed, evacuated cell is extremely demanding.

Our solution of the problem is a double absorption cell (Fig. 1): the inner vapor cell is a simple $200 \mathrm{~mm}$ long alumina tube of $15 \mathrm{~mm}$ outer diameter (1), to which the $125 \mu \mathrm{m}$ corundum windows (2) are glued with a high temperature alumina cement (Cotronics 940). The cell is not vacuum tight: the porous cement allows a slow exchange of gases. Prior to cementing, a sample of $\mathrm{Zn}$, in excess of the quantity required for filling the cell with vapor at the required absorption thickness, is introduced. (In some cells, a small hole has been drilled into the cell wall, equipped with a fitting stopper, to allow the filling in the finished cell.) The inner cell is inserted into a $445 \mathrm{~mm}$ long quartz or stainless steel tube with a diameter of $46 \mathrm{~mm}$ (3) which provides an atmosphere of helium: upon insertion, the tube is repeatedly evacuated and flushed with helium to drive the air out of the porous inner cell and prevent the oxidation of $\mathrm{Zn}$ vapor.

The outer tube is placed into a tubular oven (4) so that its end flanges (5) equipped with gas inlet (6) and aluminum foil windows (7) stick out of the oven. Baffles (8) at both ends shield the windows by suppressing the convection of the hot gas towards the ends of the tube. The resistance-heated oven of our own design is equipped with a programmable feedback controller and an additional thermocouple to read the cell temperature on-line with the absorption measurement. 
The absorption measurement was performed in the framework of $\mathrm{CH}-1298$ experiment at the BM29 station of ESRF, Grenoble, France. The resolution of the two-crystal fixed exit slit monochromator equipped with $\mathrm{Si}(111)$ crystals was estimated to be better than $0.3 \mathrm{eV}$ at $\mathrm{Zn} \mathrm{K}$-edge. A feedback loop keeping the crystals at a constant detuning was used to suppress higher harmonics. Energy calibration is independently established with simultaneous absorption measurements on $\mathrm{Zn}$ metal foil.

For an elongated sample container, the alignment with respect to the beam is a crucial parameter for the quality of data. The problem is particularly difficult in aligning the inner tube in the double cell with optically opaque windows. The base plate of the oven was mounted onto two independent pairs of $y-z$ translation tables with 3-point support on steel balls. The setup allows adjustment of the sample position in transverse horizontal $(y)$ and vertical $(z)$ direction, as well as the horizontal and vertical tilt with respect to the beam.

The double cell heated to $750{ }^{\circ} \mathrm{C}$ kept $\mathrm{Zn}$ vapor for several hours of the absorption experiment before the excess batch of $\mathrm{Zn}$ ran out. In the beginning, the spectra were rather noisy for the transient formation of the vapor. The steady regime was briefly achieved producing some absorption spectra of the $\mathrm{Zn}$ K-edge and its vicinity, comparable in sensitivity and resolution to the noble gas spectra (Fig. 2).

The surprising feature is the sharp "white line" - the pre-edge resonance corresponding to the $1 \mathrm{~s}-$ $4 p$ transition which has not been observed in spectra of any of the other states of the metal or its compounds but is a regular feature in other transition-metal vapors [16]. The height of the white line may be affected by the experimental resolution or saturation: in one of the spectra with lower vapor pressure and lower overall absorption the line is five times higher than the K-edge jump. Its shape fits a convolution of a Lorentzian with a width of $1.68 \mathrm{eV}$ (lifetime width of $\mathrm{Zn} \mathrm{K}$ vacancy $1.67 \mathrm{eV}$ [20]) and a Gaussian with a $0.26 \mathrm{eV}$ FWHM, confirming the geometrical estimate of the monochromator resolution. The coexcitations of the valence electrons can also be discerned in the spectrum above the K-edge.

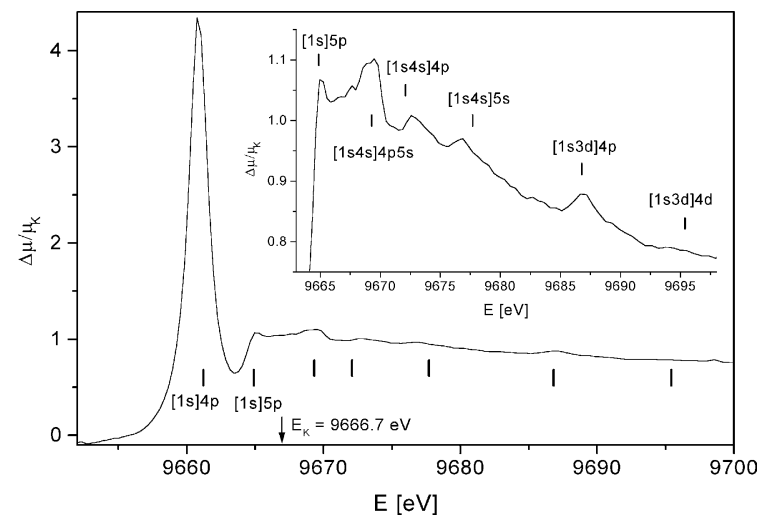

Fig. 2. The normalized absorption coefficient of $\mathrm{Zn}$ vapor in the vicinity of the K-edge. The inset shows expanded picture of single and double photoexcitations, together with corresponding Hartree-Fock energy estimates [19].

After the batch of $\mathrm{Zn}$ in the corundum cell was exhausted and during the subsequent cooling of the apparatus, the absorption spectrum showed a small and steady residue of $\mathrm{Zn} \mathrm{K}$-edge with the XAFS signal identical to that of metallic Zn. Its edge jump amounted to $1.5 \%$ of that in the vapor spectrum. The value represents an estimate of the contamination of the spectrum in Fig. 2 with a non-atomic component. The constant contribution can, however, reliably be removed from the measured spectrum before the analysis. The low degree of contamination was confirmed in the post mortem inspection of the cell when the corundum windows showed no visible trace of the metal. This may be explained by the working of the device: the temperature in the tube is efficiently equalized by the free circulation of the helium in the space between the baffles so that the windows of the inner cell are not appreciably cooler than the cell itself contrary to conventional single-wall cells where the gradient cannot be avoided.

Apart from the newly determined atomic absorption in zinc, the experiment provided a successful test of a novel cell construction. The double-cell seems promising for other less volatile elements or compounds, since the $750{ }^{\circ} \mathrm{C}$ required in the zinc experiment is not its upper limit. The basic idea is to use the high refractory cell materials without a need of welding, connecting or sealing. The inner cell is not vacuum-tight: we 
believe that even cementing of the windows is not essential and could be substituted with a good contact of polished surfaces. Thus, the windows need only combine a good transparency with the resistance to heat and aggressive vapor. There is almost no pressure difference to withstand: on heating, helium can diffuse out of the cell easily. The escape of the heavier vapor evolved at the working temperature is much slower so that a steady state, necessary for the measurement, can be reached and maintained.

\section{Acknowledgements}

We thank A. Filipponi for his suggestion concerning the sample alignment. The study is supported by the Ministry of Education, Sciences and Sport, Slovenia. The experiment at the BM29 beamline of ESRF was performed under experiment no. CH-1298.

\section{References}

[1] D. Deslattes, R.E. LaVilla, P.L. Cowan, A. Henins, Phys. Rev. A 27 (1983) 923.

[2] S.J. Schaphorst, A. Kodre, J. Ruscheinski, B. Crasemann, T. Åberg, J. Tulkki, M.H. Chen, Y. Azuma, G.S. Brown, Phys. Rev. A 47 (1993) 1953.
[3] M. Deutsch, P. Kizler, Phys. Rev. A 45 (1992) 2112.

[4] I. Arčon, A. Kodre, M. Štuhec, D. Glavič-Cindro, W. Drube, Phys. Rev. A 51 (1995) 147.

[5] J.M. Esteva, B. Gauthe, P. Dhez, R.C. Karnatak, J. Phys. B 16 (1983) L263.

[6] H.P. Saha, Phys. Rev. A 42 (1990) 6507.

[7] M. Štuhec, A. Kodre, M. Hribar, I. Arčon, D. GlavičCindro, W. Drube, Phys. Rev. A 49 (1994) 3104.

[8] M.H. Tuilier, D. Laporte, J.M. Esteva, Phys. Rev. A 26 (1982) 372.

[9] R. Prešeren, I. Arčon, M. Mozetič, A. Kodre, A. Pregelj, Nucl. Instr. and Meth. B 111 (1996) 161.

[10] R. Prešeren, A. Kodre, I. Arčon, J. Padežnik Gomilšek, M. Hribar, Nucl. Instr. and Meth. B 149 (1999) 238.

[11] J. Padežnik Gomilšek, A. Kodre, I. Arčon, R. Prešeren, Phys. Rev. A 64 (2001) 22508.

[12] A. Filipponi, L. Ottaviano, T.A. Tyson, Phys. Rev. A 48 (1993) 2098.

[13] A. Kodre, I. Arčon, R. Frahm, J. Phys. IV (France) 7 Coll. C2 (1997) 195.

[14] A. Kodre, J. Padežnik Gomilšek, I. Arčon, R. Prešeren, J. Synchrotron Radiat. 6 (1999) 306.

[15] A. Kodre, R. Prešeren, I. Arčon, J. Padežnik Gomilšek, M. Borowski, J. Synchrotron Radiat. 8 (2001) 282.

[16] U. Arp, B.M. Lagutin, G. Materlik, I.D. Petrov, B. Sonntag, V.L. Sukhorukov, J. Phys. B 26 (1993) 4381.

[17] G. Materlik, B. Sonntag, M. Tausch, Phys. Rev. Lett. 51 (1983) 1300

[18] O. Keski-Rahkonen, G. Materlik, B. Sontag, J. Tulkki, J. Phys. B 17 (1984) L121.

[19] C. Froese-Fischer, Comput. Phys. Commun. 43 (1987) 355.

[20] M.O. Krause, J.H. Oliver, J. Phys. Chem. Ref. Data 8 (1979) 329. 